\title{
COVID-19 Containment in Asia's Largest Urban Slum Dharavi-Mumbai, India: Lessons for Policymakers Globally
}

\author{
Mahaveer Golechha
}

Published online: 19 August 2020

(C) The New York Academy of Medicine 2020

The World Health Organization declared the outbreak of coronavirus disease 2019 (COVID-19) on March 11, 2020, highlighting the importance of preventive measures to limit the transmission of infections [1]. The COVID-19 pandemic has evoked dramatic global disruption and has placed immense burdens on healthcare systems globally.

The close to one billion people are living in urban slums across the globe. Slums and informal settlements have emerged as hotspots for COVID-19 transmission. The urban slums are highly susceptible to COVID-19 infection due to short supply or unavailability of adequate water, toilets, sewers, drainage, waste management systems, housing, and other basic necessities [2].

The challenges of slum communities are not new, but during the COVID-19 pandemic, they demand innovative solutions more urgently than ever for containing spread of virus.

The public health policymakers and other governmental agencies are struggling to manage this historic medical event [3] and looking for potential solution to contain this pandemic, especially in limited resource settings.

Dharavi, Asia's largest and densely populated urban slum, has successfully contained the COVID-19 with its

M. Golechha $(\bowtie)$

Health Systems and Health Policy, Indian Institute of Public Health-Gandhinagar, Opp. Airforce Head Quarters, Nr. Lekawada Bus Stop, Gandhinagar - Chiloda Road, Gandhinagar 382042, India

e-mail: mahaveeraiims@yahoo.co.in innovative public health policy response. The municipal administration called this model as "chasing the virus" rather than waiting for people to report it.

The WHO has also acknowledged on Dharavi's success in controlling the virus spread and mentioned that "Dharavi should be seen as an example across the world." The WHO has also stated that the Dharavi model is based on community engagement, testing, tracing, isolating, and treating for breaking the chain of transmission.

Dharavi, a sprawling slum in the heart of Mumbai, India's financial and entertainment capital, has an area of just over $2.1 \mathrm{~km}^{2}\left(0.81 \mathrm{mi}^{2} ; 520\right.$ acres $)$ and a population of about a million. With a population density of over $277,136 / \mathrm{km}^{2}\left(717,780 / \mathrm{mi}^{2}\right)$, Dharavi is one of the most densely populated areas in the world.

Dharavi reported its first corona positive case on April 1, the policymakers and officials feared that the slum will become the biggest hotspot of COVID-19 in India considering its geography, health inequalities, and flaring economic and social disparities. Dharavi had a surge of COVID-19 outbreak, and the virus started spreading at the local and community level. The number of new coronavirus cases increases exponentially peaking at 491 new infections on April 30. The local population worried that soon Dharavi will become New York of the USA or Lombardy of Italy.

Dharavi had 491 cases in April 2020 with a 12\% growth rate and a case doubling period of 18 days. The public health measures and proactive strategy adopted by municipal administration helped in reducing the COVID-19 growth rate to $4.3 \%$ in May 2020 and further 
to $1.02 \%$ in June [4]. These strategies also ensured an improved case doubling time to 43 days in May 2020 and 78 days in June 2020 [4]. For the first time since the first week of April, the slum has recorded just one case on July 7. There are 2335 positive cases and 352 active cases in Dharavi as on July 7, 2020. Dharavi has also registered an impressive tally of recoveries with 1735 patients who have recovered [5].

Immediately after detection of first case on April 1, the local municipal acted swiftly. The municipal corporation barricaded the entrance and exit to the slum cluster, carried out disinfection of 425 public toilets, and began door-todoor screening, robust surveillance, engaging private doctors in containment activities, partnering with NGOs for building community trust and providing food to needy population, ramping up quarantine and treatment facilities, and implementation of strictest lockdown to slow down the spread of the pandemic.

The Dharavi model becomes the template for the policymakers and public health practitioner globally for breaking the chain of transmission and flattening the curve in densely packed urban slum communities around the world. This is also important to note that Dharavi model is ideal of setting where social distancing is impossible or difficult to follow.

Dharavi was able to successfully flatten the curve in 2 months with its COVID-19 response strategy of actively following four T's - tracing, tracking, testing, and treating. This approach included activities like proactive screening and robust surveillance.

The Dharavi containment strategy was largely based on WHO's pillars of the public health response for COVID19 , suggested in its operational planning guidelines to support country preparedness and response [6]. The administration also integrated Kerala model of COVID-19 prevention in its strategy to contain the pandemic.

Considering the success of Dharavi model of COVID-19 containment with "chase the virus" strategy, it is worthwhile to explore various steps taken and response strategy implemented by the government and policymakers. The Dharavi model employed following steps for curbing the pandemic (Fig. 1).

\section{Governance, Multi-sectoral Coordination, and Stringent Lockdown}

Efficient and effective governance is an essential component of a well-planned pandemic control response.
The state government has acted swiftly and coordinated effectively from state headquarter. Several public health teams and technical experts were deployed to Dharavi with continuous monitoring by state government leadership including the chief minister, health minister, and senior bureaucrats. The multi-sectoral approach to pandemic preparedness emphasizes the significant roles played not only by the health sector but also by all other sectors, individuals, families, and communities, in mitigating the effects of a pandemic [7]. Outbreak response requires coordination at all levels. The municipal administration collaborated with other line departments for various containment activities, especially door-doorscreening, risk communication, and supply of essential groceries. This multi-sectoral approach has ensured the effectiveness of lockdown.

The municipal administration imposed a curfew (stringent lockdown) and sealed the border of slum with 24 check-posts set up at all entry/exit points to monitor movement control. Strict containment measures were deployed in virus hotspots, including the use of drones to monitor their movements and alert police, while a huge army of volunteers swung into action for implementing containment measures. All forms of transportation services and movement of vehicles were stopped; small industries, shops, and markets across the slum area were shut down with immediate effect. The officials zeroed in on five zones that they deemed high risk due to initial infections and patients. Around the clock war room was established for monitoring every aspect of tracing, testing, quarantine, and lockdown in the containment zones.

Undoubtedly, lockdown is an effective strategy for containing the transmission of infection. However, this is very challenging with added difficulty for larger sections of the society. The social distancing is very difficult people living in slum areas; the daily wage earner has to earn daily money to keep the family alive [8]. India's slum areas, health inequalities, flaring socioeconomic disparities, and distinct cultural values had made lockdown a hard measure for the poorer sections of the society [8]. The stringent lockdown has maximized economic loss and simply debilitated the slum population of daily wage earners and migrant laborers. Most of them, with little or no savings, had to step out daily amid the lockdown to either arrange for food and essential items or collect food packets. For effective implementation of lockdown and reducing the discomfort to the public due to stringent lockdown, the administration has 


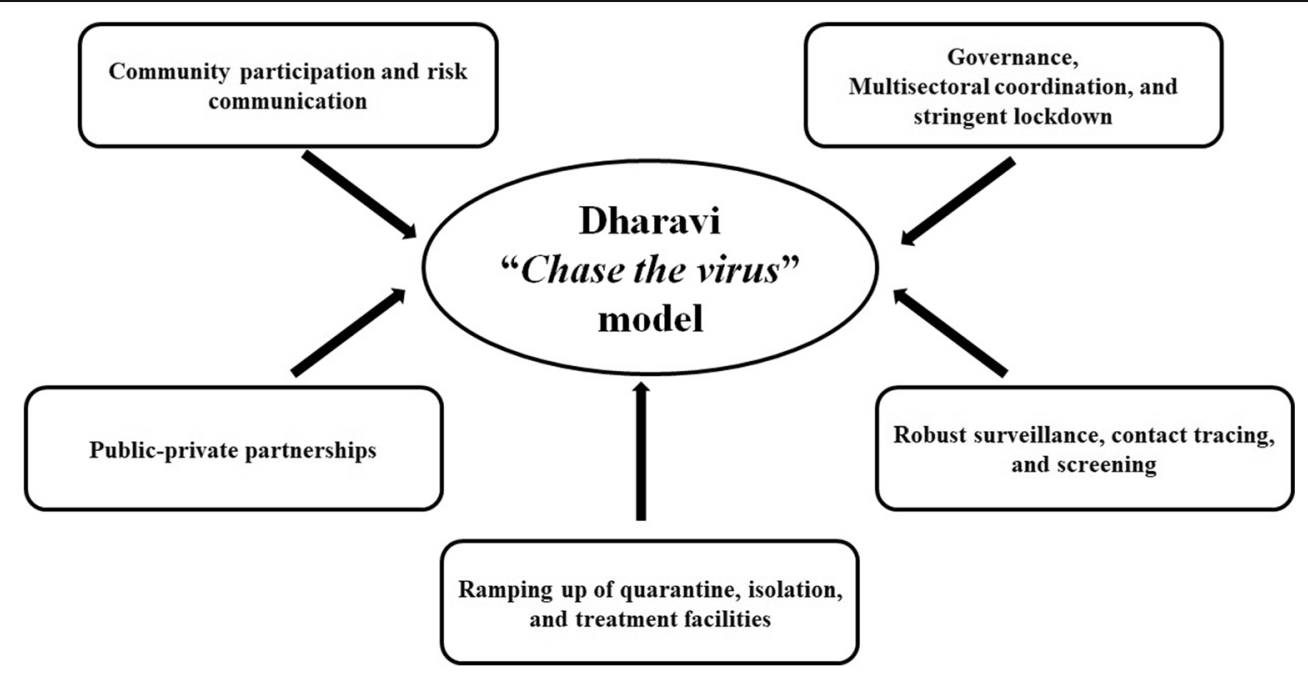

Fig. 1 COVID-19 containment model of Dharavi

ensured door-to-door regular supplies of milk, vegetables, grocery, and other essentials. The administration has set up control rooms of several departments for fulfilling population demands. Further, about 100,000 migrant workers and their families had left Dharavi after a nationwide lockdown was announced. The exodus of migrant labors has also helped the authorities in containing the spread of coronavirus.

\section{Robust Surveillance, Contact Tracing, and Screening}

Surveillance during the pandemic is pivotal for the core information on which pandemic-response decisions are based. It enables the development and implementation of evidence-based interventions during a pandemic event [9]. It seems impossible to control the spread of infection and community transmission in an area, where 9-10 people stay in a $10 \times 10 \mathrm{ft}^{2}$ room.

The government deployed the army of nearly 2500 doctors and healthcare workers of Mumbai's overburdened public health system to Dharavi's narrow alleys. The healthcare workers stuffed with personal protective equipment (PPE) suits knocking on door after door for screening, paying particular attention to houses or workspaces in the vicinity of positive cases. It was test-trace-isolate-repeat approach initially implemented in Dharavi. The teams were assigned clusters and zones to assiduously and aggressively conduct the testing-andtracing drill. The municipal teams carried out screening of 47,500 people through door-to-door screening. Many healthcare workers reported non-responsiveness from citizens on ground of trust deficits and considering civic body workers as outsiders. The municipal administration roped in 350 private and local practitioners, which are considered insider and trustworthy. The municipal administration has also opened several fever clinics for screening and testing of population for any symptoms of Influenza-like illnesses (ILI). Due to limited resources available for testing, the teams decided to use oximeters to check oxygen level for catching the hold of people with low levels of oxygen. The population was checked and re-checked with thermal scanners and oximeters. Anyone with symptoms would be sent for lab tests and quarantined. Within few weeks, municipal teams had completed gargantuan task of screening 548,270 people in Dharavi, including 1,20,000 senior citizens, who are more vulnerable to the infection. The suspected cases were shifted to well-organized COVID care centers and quarantine centers. All contacts staying in slum settlements and used community toilets were considered high risk and shifted to quarantine facilities. Due to timely screening, early isolation and continuous monitoring have ensured low mortality rate in Dharavi.

\section{Ramping up of Quarantine, Isolation, and Treatment Facilities}

Along with surveillance and screening, the administration was building the infrastructure to meet the consequences of community transmission. Around $80 \%$ of its 
people depend on community toilets, and eight to ten people live in households or hutments just $10 \times 10 \mathrm{ft}$.

Such limitations in physical distancing made effective home quarantine impossible. Therefore, ramping up of quarantine facilities was essential to halt the spread of transmission. For those who are not infected or not came into contact with infected people were using existing community toilets. Therefore, the administration has carried out a special sanitation drive and disinfection campaign in the entire slum area; special attention been given to public toilets. The teams were disinfecting every nook and corner of the slum community for containing the transmission.

While contact tracing was one measure, setting up large quarantine centers was the complementary factor. The administration has converted schools, marriage halls, and community centers into nine quarantine facilities with food, regular checkups, and free healthcare and testing. The first large facility that the administration took over in Dharavi was the Rajiv Gandhi Sports Complex with 300 beds. A total of 9500 people have been placed under quarantine. Due to isolation and uncertainties about the infection, people quarantined were under enormous mental health crisis. The administration organized yoga, aerobics, and breathing exercise session for boosting immunity and reducing mental stress. The administration then took the unprecedented step of taking control of five private hospitals along with their staff and medical equipment to treat high risk COVID-19 patients. The capacity building of healthcare professionals has been carried out to meet the clinical treatment and management of COVID-19 cases by state and district rapid response teams (RRTs).

\section{Public-Private Partnership (PPP)}

The coronavirus pandemic has shown us the importance of public and private sectors partnership during an emergency response [10]. Pandemics, like COVID-19, necessitate catalyzing make-shift and long-term PPPs to remediate unprecedented burdens on the healthcare system.

The municipal administration has also leveraged the vast potential of PPP in Dharavi for containing the spread of COVID-19. The administration foraging public-private partnerships with various civil society organizations and local medical association for surveillance, tracing, screening, and arranging food for needy population. The private practitioners were brought to create an environment for local residents to come out and report symptoms. The municipal administration provided PPEs to all local doctors and asked them to open clinics. Every week, authorities hand over a 7-day supply of PPEs to doctors. With the help from local doctors, fever makeshift clinics and medical camps were organized to screen high risk and vulnerable population. The 350 local practitioners worked as a bridge between municipal officials and the people in Dharavi. People had faith in the local doctors and followed their instructions diligently. Irrespective of their symptoms, all patients were screened for fever, and their oxygen saturation levels were checked by local practitioners. The PPP approach yields rich dividends and helped the administration significantly in controlling the pandemic.

\section{Community Participation and Risk Communication}

Community participation and ownership are always crucial for controlling the pandemic and other epidemic outbreaks [6]. Slum leaders play an important role in solving problems of residents; therefore, understanding their role and activities are pivotal to community-driven approaches to contain the transmission of virus. The municipal corporation identified and collaborated with local influential leaders, community organizations, and NGOs for easy access to the area and residents. Hundreds of volunteers, designated as "COVID warriors," joined hand with administration for ensuring regular supplies of essential groceries and medicine in containment zones. Further, some community volunteer equipped with thermal scanner and pulse oximeter also helped in screening efforts. The officials in proactive collaboration with social workers, philanthropists, and industrialists arranged PPEs, oxygen cylinders, gloves, masks, medicines, and ventilators. Community kitchens provided breakfast, lunch, and dinner to those housed in the quarantine centers. A key feature of the containment strategy was ensuring uninterrupted supply of essential food items and groceries. Around $70 \%$ of Dharavi's population comprises daily wage earners, most of them, with little or no savings. With the help of NGOs and philanthropist, essential ration and food packets were arranged for needy population. This approach has generated significant community capacity to respond to resiliently during the coronavirus crisis.

The administration has ensured that people have the right information, delivered in the right way, to take 
appropriate and proportionate steps to protect themselves. The municipal administration set up a helpline number for providing timely and accurate information to the population. Clear data-driven communication about preventive steps and preparedness was ensured by administration to build people confidence. The risk communication and community participation helped authorities to contain the pandemic with humanistic approach.

\section{Conclusion}

Currently, as the pandemic is emerging, many new insights and strategies are evolving from best practices deployed by many countries. This article discusses how Dharavi being once a coronavirus cluster become successful in containing the COVID-19. The Asia's largest slum has come a long way in its fight against the pandemic. The "Dharavi model" has been so successful in curbing the spread of COVID-19 in a hotspot that the other states are replicating this model, and central government has also asked other Indian states to replicate its model of "chasing the virus." Dharavi has shown that irrespective of aggravating circumstances, it is possible to considerably slow down or pause the virus transmission by literally chasing it down, with micro-mapping, robust surveillance, public-private partnership, community engagement, and proactive leadership.

Many nations with well-functioning resourced health systems, like South Korea, Japan, New Zealand, Taiwan, and Czech Republic, have also successfully contained the COVID-19; however, their strategy may not be feasible for resource-limited settings. But, the Dharavi model can be implemented in resource-limited settings. Therefore, the Dharavi COVID-19 containment model of dogged legwork, visionary leadership, proactive thinking, efficient governance, public private partnership, and community engagement could offer lessons for other poor, densely packed urban slum communities around the globe.

This pandemic could be an opportunity for policymakers to make cities more inclusive and resilient. There is an urgent need to improve the availability of basic services in slums for not only improving living conditions but also strengthening public health and building the local economy. The government also needs to improve access to education, public health, safety, and economic opportunity for all in slum areas.
Acknowledgments The author is project lead of NITI Aayog, Government of India funded project on National Health Mission Evaluation, and project lead of Heat Action Plan project funded by DST, Government of India and also Public Health Research Initiative Fellow of DST, Government of India at Public Health Foundation of India. The funding agencies do not have any role in influencing author views.

Author's Contributions Mahaveer Golechha has developed the concept, gathered the various information, and developed initial draft and also wrote the manuscript.Data AvailabilityData sharing is not applicable to this article as no datasets were generated or analyzed during the current study.

\section{Compliance with Ethical Standards}

Competing Interest The authors declare that they have no conflict of interest.

Ethics Approval and Consent to Participate Not Applicable.

Consent for Publication Not applicable.

\section{References}

1. Nomura S, Yoneoka D, Tanoue Y, Kawashima T., Shi S., Eguchi A., Miyata H. Time to reconsider diverse ways of working in Japan to promote social distancing measures against the COVID-19 [published online ahead of print, 2020. J Urban Health. 2020;1-4. https://doi.org/10.1007 /s11524-020-00464-4.

2. Corburn J, Vlahov D, Mberu B, Riley L, Caiaffa WT, Rashid SF, et al. Slum health: arresting COVID-19 and improving well-being in urban informal settlements. $J$ Urban Health. 2020;97(3):348-57. https://doi.org/10.1007 /s11524-020-00438-6.

3. Golechha M. India should ramp up its emergency medicine and critical care infrastructure to combat COVID-19 [published online ahead of print, 2020 Jun 19]. Postgrad Med J. 2020;postgradmedj-2020-138249. https://doi.org/10.1136 /postgradmedj-2020-138249.

4. Press Information Bureau, Government of India. COVID-19 Updates. 2020; Available at https://pib.gov. in/PressReleseDetail.aspx?PRID $=1633177$. Accessed 8 July 2020.

5. Public Health Department, Government of Maharashtra. 2020; Available at https://arogya.maharashtra.gov.in/1175 /Novel\%2D\%2DCorona-Virus. Accessed 8 July 2020.

6. WHO. 2019 Novel Coronavirus (2019-nCoV): strategic preparedness and response plan. Geneva, Switzerland, 2020. Available at https://www.who.int/publicationsdetail/strategic-preparedness-and-response-plan-for-thenew-coronavirus. Accessed 7 July 2020. 
7. Pandemic Influenza Preparedness and Response: $A$ WHO Guidance Document. Geneva: World Health Organization; 2009. 3, roles and responsibilities in preparedness and response. Available from: https://www.ncbi.nlm.nih. gov/books/NBK143067/. Accessed 7th July 2020.

8. Golechha M. COVID-19, India, lockdown and psychosocial challenges: What next? [published online ahead of print, 2020 Jun 13]. Int $J$ Soc Psychiatry. 2020;20764020935922. https://doi.org/10.1177 /0020764020935922.

9. WHO guidance for surveillance during an influenza pandemic: 2017 update. Geneva: World Health Organization; Available at https://www.who.int/influenza/preparedness/ pandemic/WHO_Guidance_for_surveillance_during_an influenza_pandemic_082017.pdf. Accessed 7 July 2020.
10. Tolchinsky A. Why public-private partnerships strengthen our public health response. CDC Foundation News. 2020. Available at https://www.cdcfoundation.org/blog/whypublic-private-partnerships-strengthen-our-public-healthresponse. Accessed 7 July 2020.

Author is alumnus of AIIMS, New Delhi, India; London School of Hygiene and Tropical Medicine (LSHTM), UK and London School of Economics (LSE), UK.

Publisher's Note Springer Nature remains neutral with regard to jurisdictional claims in published maps and institutional affiliations. 